\title{
Analysis of Key Factors Affecting Water Disaster in Deep Mining and Establishment of a Water Disaster Evaluation Method Suitable for Different Mining Depths
}

\author{
Jianghui He $\mathbb{D}^{1},{ }^{1}$ Wenping Li $\mathbb{D},{ }^{1}$ Wei Qiao, ${ }^{1}$ Zhi Yang, $^{2}$ and Qiqing Wang $\mathbb{D}^{1}$ \\ ${ }^{1}$ School of Resources and Geosciences, China University of Mining \& Technology, Xuzhou 221116, China \\ ${ }^{2}$ School of Environment and Spatial Informatics, China University of Mining \& Technology, Xuzhou 221116, China \\ Correspondence should be addressed to Wenping Li; hjh@cumt.edu.cn
}

Received 5 April 2021; Revised 24 May 2021; Accepted 16 June 2021; Published 6 July 2021

Academic Editor: Wei Zhao

Copyright (c) 2021 Jianghui He et al. This is an open access article distributed under the Creative Commons Attribution License, which permits unrestricted use, distribution, and reproduction in any medium, provided the original work is properly cited.

\begin{abstract}
Deep mining is the current and future mining focus in the coalfield of North China. Therefore, it is necessary to establish a water inrush assessment method suitable for deep mining. The conventional water inrush coefficient $(T)$ method is simple to use, but its accuracy is low when the mining depth is very small or large because it neglects the role of the aquifer water yield. The main purpose of this paper is to introduce a simple water inrush risk assessment method that is more applicable in deep mining than the $T$ method. In this study, the hydrogeological characteristics in deep mining were studied and the role of the aquifer water yield in water inrush was analyzed. Afterwards, an improved $T$ method considering the aquifer specific yield $(q)$ was established. In the new method, the critical water inrush coefficient changes with changing $q$ following a negative correlation. The parameter thresholds were determined based on systematic data analyses of 186 mining cases. The results of the statistical analysis show that the accuracy of the new method at different mining depths is higher than that of the $T$ method.
\end{abstract}

\section{Introduction}

Coal will remain the major energy source in China for a long time. From the coal resources in China, 53\% are located below a depth of $1 \mathrm{~km}$ [1]. Following the depletion of shallow coal resources, the coal mining depth $\left(D_{m}\right)$ has increased. However, the exploitation of deep coal seams in the North China coalfield (Figure 1) faces a threat from the underlying confined aquifers in Ordovician limestone.

Floor karst water inrush has been extensively studied in literature. For example, $\mathrm{Wu}$ et al. have conducted extensive and detailed research on water inrush from mine floors, proposing some risk-assessment methods, such as the mastercontrol index method and the vulnerability index method and its improved version $[2,3]$. These methods were successfully applied to practical mining. Liu and $\mathrm{Hu}$ adopted the water-resistance coefficient method to identify floor water inrush risks [4]. Meng et al. presented a geologicalassessment method to evaluate the vulnerability of the floor water inrush by considering its lithology, structure, and water inrush coefficient [5]. Wang et al. used a secondary fuzzy comprehensive evaluation system to analyze the risk of mine water inrush [6]. He et al. developed a $P-H-q$ evaluation system for risk assessment of water inrush based on the water-pressure-transfer theory [7]. Hong-fei et al. established a coal floor water inrush model that considered the structural characteristics of floor strata to evaluate the antipermeability strength of an aquiclude [8]. Bai et al. explained the groundwater inrush mechanism in terms of variable mass and nonlinear dynamics [9]. Chen et al. used an engineering analogy method to predict the water inrush risk areas in mining, using Fisher's discriminant analysis [10]. Physical simulations performed by Zhang et al. revealed that the permeability of floor rocks had regional and temporal characteristics [11]. Gao et al. found that the water inflow increased with an increasing permeability coefficient following a power function [12]. Many other methods are available to evaluate the possibility of mine water inrush and related water-rock coupling problems [13-34]. Some scholars have specially studied floor water inrush through faults [35-39]. In 


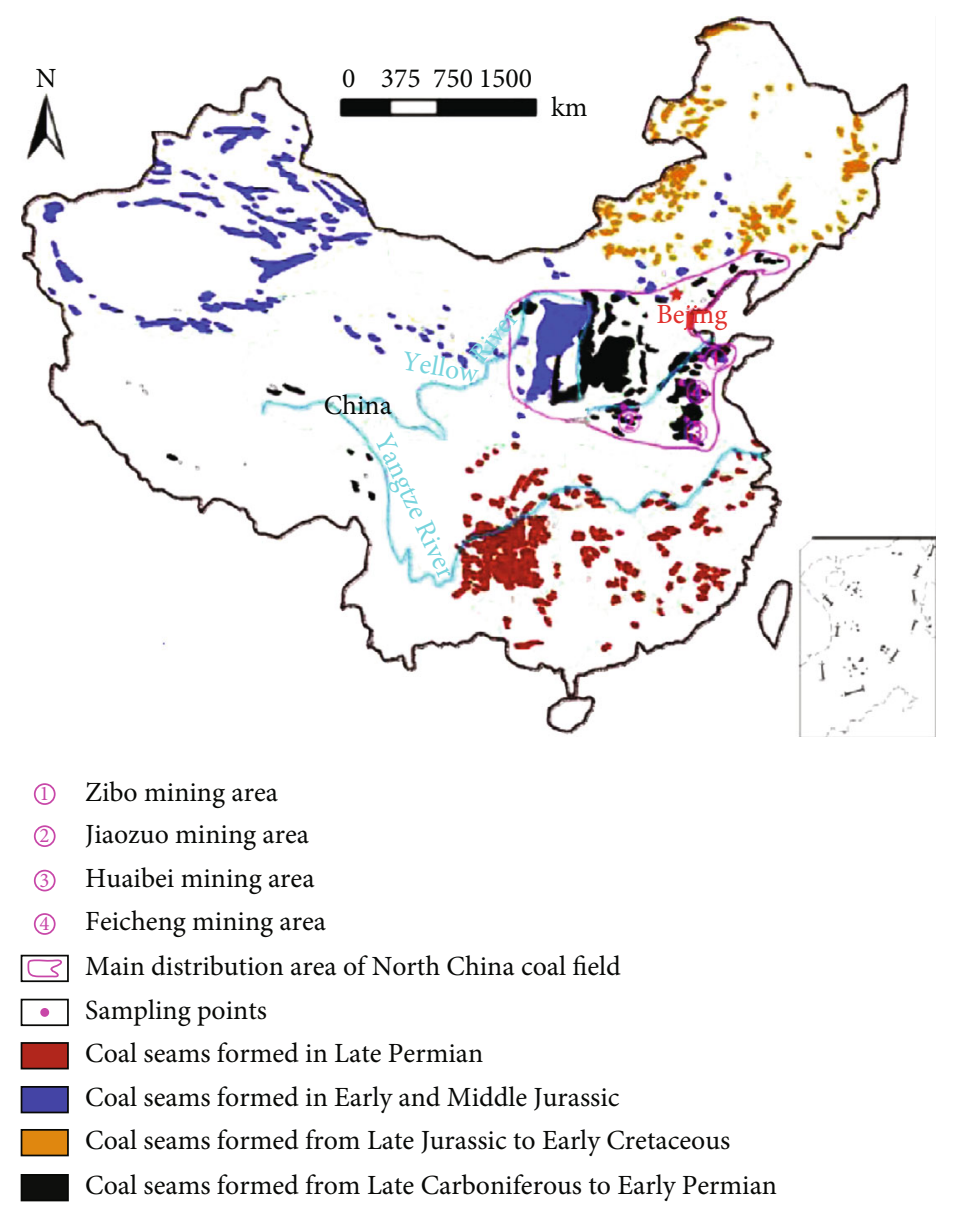

FIGURE 1: Distribution of coal resources in China.

summary, the common methods used to predict the mine floor water inrush can be categorized as (1) empirical formula and GIS technology, (2) mathematical analysis, (3) nonlinear mathematical analysis, and (4) simulation experiments [40]. However, most of these methods require sophisticated software, equipment, and/or operational technology as well as complex analyses and calculations. Therefore, widespread implementation of these methods is difficult.

The conventional water inrush coefficient $(T)$ method is the most practical method used to predict water inrush in coal mines under various conditions. $T$ (in $\mathrm{MPa} / \mathrm{m}$ ) is obtained from the following empirical equation based on large water inrush data:

$$
T=\frac{P}{M},
$$

where $P$ (in $\mathrm{MPa}$ ) is the water pressure in a confined aquifer in the coal-seam floor and $M$ (in $\mathrm{m}$ ) is the thickness of the aquiclude of the coal seam floor.

$T$ denotes the water pressure that can be supported by a unit thickness of the coal seam floor aquiclude and can quantitatively indicate the risk of water inrush from an underlying confined aquifer during coal mining. A larger $T$ value indicates more susceptibility to water inrush accidents. The minimum value of $T$ that can initiate water inrush is called the critical water inrush coefficient $\left(T_{s}\right)$, which ranges from 0.06 to $0.1 \mathrm{MPa} / \mathrm{m}$, as provided in the Stipulation on Prevention and Control of Coal Mine Water of China [41]. Floor water inrush incidents are likely to occur when $T>T_{s}$. This formula is simple and practical because it incorporates two important parameters that govern the characteristics of the aquifer and aquiclude ( $P$ and $M$, respectively). Therefore, it has been incorporated in relevant standards and coal mine water prevention and control regulations.

Practical mining data collected from the North China coalfield, which include 186 water inrush cases and 92 safety mining cases, have proven that the results predicted using the $T$ method are generally consistent with the actual results when $2.5 \mathrm{MPa}<P<3.5 \mathrm{MPa}$ (Figure 2).

In addition, according to the data collected from the North China coalfield [42], $P$ exhibits a linear positive correlation with the aquifer depth $(D)$ (Figure 3 ).

The following equation can be obtained from Figure 3:

$$
D=101.28 P+11.212
$$

Because $D$ will change with $D_{m}$ (Figure 4 ), it is necessary to analyze the change in the accuracy of the $T$ method with changing $D_{m}$. 


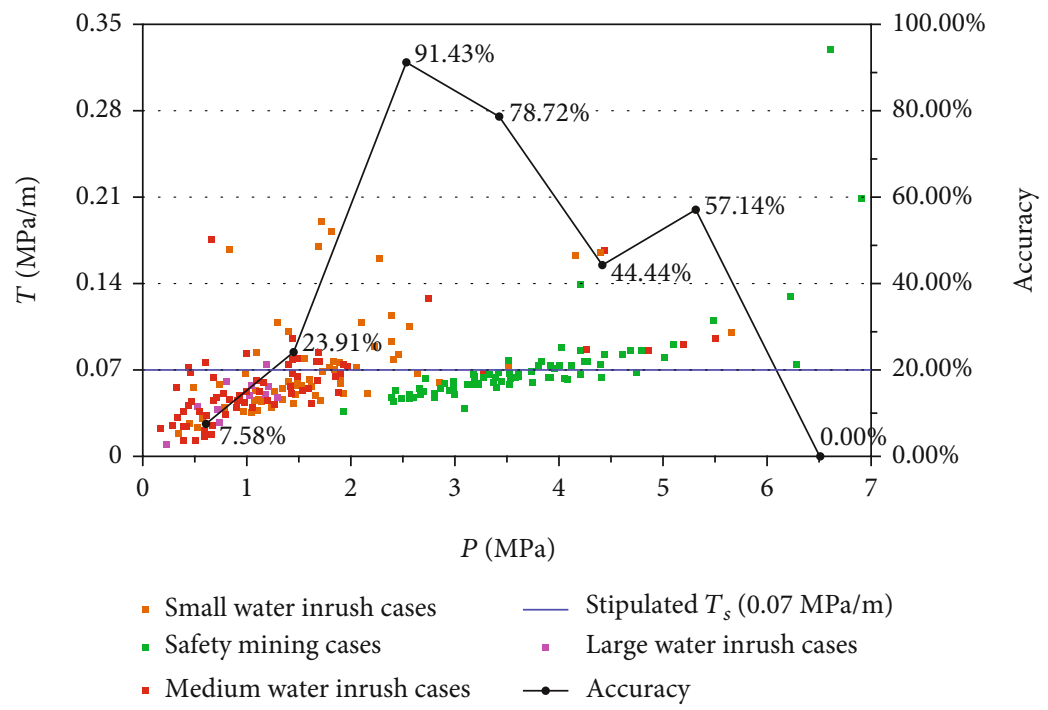

FIGURE 2: Change in the accuracy of the prediction results from the water inrush coefficient method $(T)$ under different water pressures $(P)$.

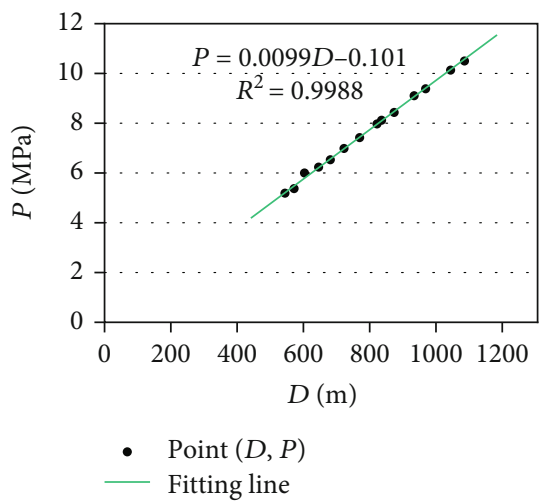

FIGURE 3: Distribution of the water pressure $(P)$ at different depths (D).

Figure 4 shows that the relationship between $D$ and $D_{m}$ can be expressed by the following formula:

$$
D_{m}=D-M
$$

After statistically analyzing the data in Figure 2 with the help of Equations (2) and (3), the variation of the prediction accuracy from the $T$ method with changing $D_{m}$ can be obtained (Figure 5).

The $T$ method was put forward in 1964 in Jiaozuo's hydrogeological work. The corresponding $T_{s}$ was also the empirical value based on the mining conditions at that time. Because the average value of $D_{m}$ was about $300 \mathrm{~m}$ at that time, the empirical value of $T_{s}$ obtained according to the mining conditions at that time was more suitable when $D_{m}$ was about $300 \mathrm{~m}$. This conclusion is basically consistent with the law of fitting line in Figure 5, which shows that the accuracy of the $T$ method is the highest when $D_{m}$ is equal to $311.16 \mathrm{~m}$. Figure 5 shows that when $D_{m}$ is very shallow or very deep, the prediction accuracy from the $T$ method is very low. Because coal seams buried at great depths are the object of future exploitation in the North China coalfield, evaluation of water hazards during mining of deeply buried coal seams is the focus of the present study. The $D_{m}$ of deeper coal seams is generally more than $400 \mathrm{~m}$, mostly exceed $700 \mathrm{~m}$, or exceed $1000 \mathrm{~m}$ in the 33 mines in the North China coalfield [43]. Hence, the $T$ method is unsuitable for deep-mining risk assessment.

In addition to the $T$ method, a common method is the GIS-based multifactor superposition analysis (represented by the vulnerability index method). The GIS-based multifactor superposition analysis method is a good method because many related factors are considered. However, in the discriminant map obtained by this method, we can only obtain the relative magnitude of water inrush risk in different positions, but not the absolute magnitude of the possibility of water inrush in different positions. When applying the GISbased multifactor superposition analysis method, a specific boundary which can divide the safety zone and water inrush zone is needed, such as $T_{s}$ in the $T$ method. Therefore, it is necessary to study the hydrogeological conditions in deep mining and to establish a simple water inrush risk assessment method that is more applicable than the $T$ method.

\section{Hydrogeological Conditions in Deep Mining}

The coal seams in some mines are buried at depths of $1,200 \mathrm{~m}$ and face the threat of limestone aquifers (Figure 6), which cause the $P$ and $T$ values to reach $13 \mathrm{MPa}$ and $0.144-1.256$ $\mathrm{MPa} / \mathrm{m}$, respectively. In addition, when $D$ is large, aquifers have low porosity $(\oint)$ and permeability $(K)$ owing to high ground stress (Figures 7 and 8 ). $\Phi$ determines the size of the water-storage space in aquifers, and $K$ determines the movement efficiency of water in aquifers. Reduced $\oint$ and $K$ lead to a reduced water yield (or effluent capacity) of the aquifer.

The water yield of aquifers is often described in terms of the specific yield $(q$, in $\mathrm{L} /(\mathrm{s} \cdot \mathrm{m}))$, which indicates the sustainable water yield from a drill hole with a diameter of $91 \mathrm{~mm}$ 


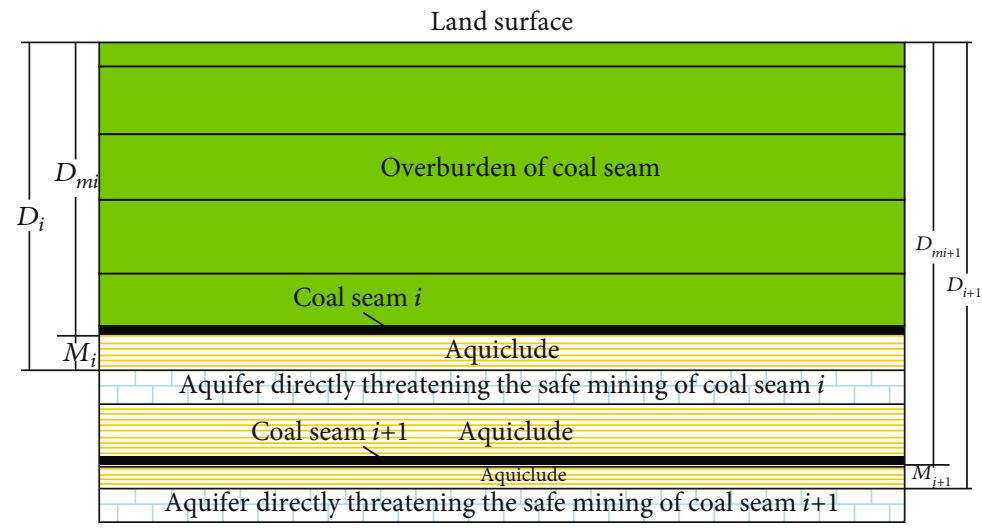

Figure 4: Relationship between $D$ and $D_{m}$. $D_{i}$ : buried depth of the aquifer directly threatening the safety mining of coal seam $i ; D_{m i}$ : mining depth of the coal seam $i ; M_{i}$ : thickness of the aquiclude directly protecting the safe mining of coal seam $i$.

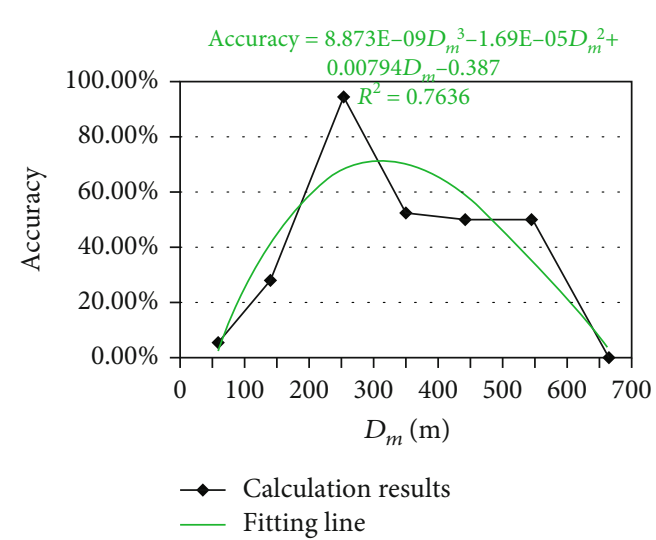

FIGURE 5: Change in the prediction accuracy of the $T$ method with changing $D_{m}$.

when the water levels drop by $1 \mathrm{~m}$ per unit time during a pumping test. Figure 9 shows a steady-flow pumping test in a confined aquifer. In this figure, $h_{0}, Q, R_{0}, s_{w}, R_{W}, a$, and $K$ denote the initial water head of the confined aquifer, the pump flow, the radius of the cone of depression, the drop of the water level in the well, the radius of the pumping well, the thickness of the aquifer, and its permeability, respectively. Under these conditions, the Dupuit formula of the confined pumping well can be obtained as follows:

$$
Q=\frac{2 \pi K a s_{w}}{\ln \left(R_{0}-R_{w}\right)} .
$$
follows:

According to the definition of $q$, it can be calculated as

$$
q=\frac{Q}{s_{w}}=\frac{2 \pi K a}{\ln \left(R_{0}-R_{w}\right)} .
$$

The value of $q$ decreases with increasing $D$ because both $\oint$ and $K$ decrease (Figure 10). Qiao et al. and Zhao reached the same conclusion $[44,45]$.

\section{Analysis of the Role of $q$ in the Occurrence of Water Inrush}

$q$ reflects the effluent capacity of the aquifer. The water inrush process involves draining water from the aquifer to other spaces. Therefore, theoretically, $q$ is closely related to the occurrence of water inrush. In contrast, water scarcity significantly reduces the likelihood of the confined water to break through an aquiclude. Some mining cases have proven that water inrush is related to the $q$ value. When the $T$ method is used to evaluate the risk of water inrush, unrealistic results are produced if $q$ is neglected (Table 1). The list in Table 1 indicates that from the first to the fifth cases, because the $q$ values were all small, no water inrush occurred, although $T>T_{s}$. From the sixth to the tenth cases (Table 1), $q$ was large and water inrush occurred during the mining process, although $T$ did not exceed $T_{s}$. Therefore, it is confirmed that $q$ significantly influences the occurrence of water inrush. Thus, in order to improve the accuracy of the results, the change in $q$ in deep mining must be considered. Shi et al. reached the same conclusion [46].

This analysis revealed that under deep mining conditions, the aquifer related to water inrush is characterized by large $P$ and low $q$, and $q$ is positively correlated with the possibility of water inrush. Therefore, in deep mining, the possibility of water inrush can be reduced using small $q$, even if $T>T_{s}$. Thus, the conventional $T$ method is oversimplified for assessing the water inrush possibility because it only considers $P$, while neglecting $q$. The water yield of aquifers that recharge the mine must be considered to accurately assess water inrush risk. Therefore, the objectives of this study are to analyze the role of $q$ in water inrush and to establish a convenient method for water inrush risk assessment that considers $q$.

3.1. Before Formation of Water Inrush. From the point of view of mechanics, the floor water inrush involves breaking the aquiclude under continuous water pressure within a certain period followed by the gushing of water from the aquifer below the aquiclude, along the rupture surface, into the goaf. Because the aquiclude breakage only occurs after a period of deformation, a time limit exists for the occurrence of water 


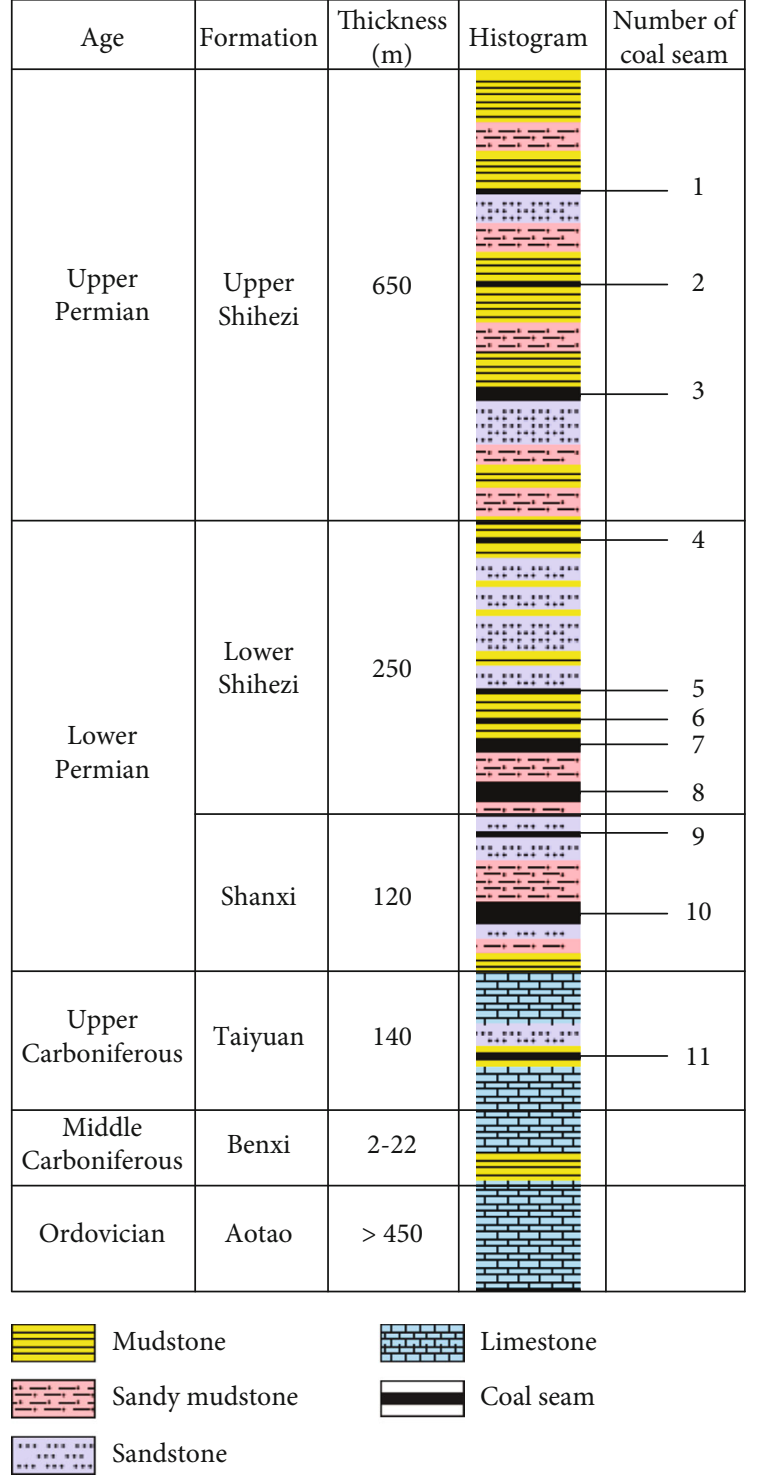

FIgURE 6: Stratigraphic column of the Permian coal-bearing strata in the Huaibei mining area, China.

inrush. First, the aquiclude takes time to deform to its critical breaking state. After a goaf with length $L$ is formed, the aquiclude gradually bends and deforms under the water pressure to reach its critical breaking state. The time required to reach this condition is called required time $\left(t_{r}\right)$. Second, the deformation and breaking of the aquiclude must be completed before the goaf is filled and compacted by the caved overburden $[47,48]$. The time before the goaf is filled and compacted is called the available time $\left(t_{a}\right)$ for water inrush formation. Water inrush can only occur when $t_{r}<t_{a}$.

The water pressure that is continuously exerted on the aquiclude, called the aquiclude bending pressure $\left(P_{b}\right)$, constitutes the external force directly responsible for the eventual breakage of the aquiclude. $P_{b}$ also refers to the water pressure accumulated in the cavity caused by the deformation of the aquiclude (i.e., (3) in Figure 11). Unless otherwise stated, this is the cavity referred to hereafter. $P$ refers to the water pressure or undisturbed water pressure in the confined aquifer

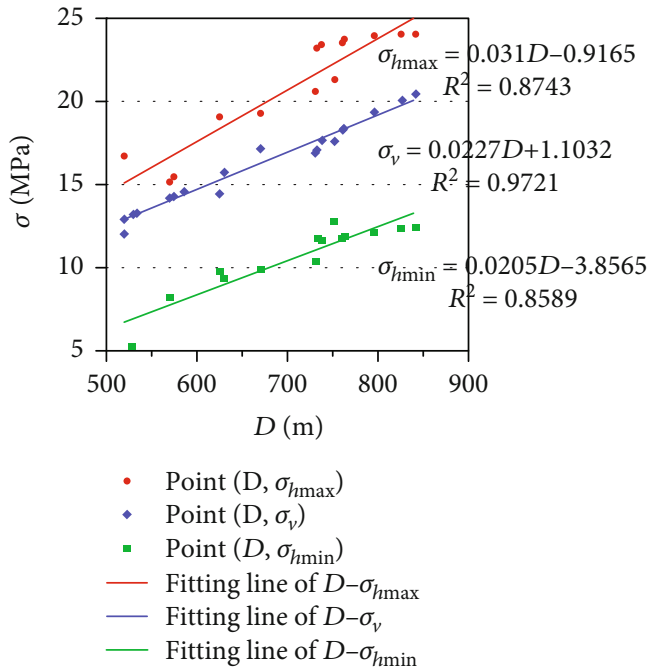

Figure 7: Changes in ground stress $(\sigma)$ at different depths $(D)$ : $\sigma_{h \max }:$ maximum horizontal principal stress; $\sigma_{h \min }$ : minimum horizontal principal stress; $\sigma_{v}$ : vertical principal stress.

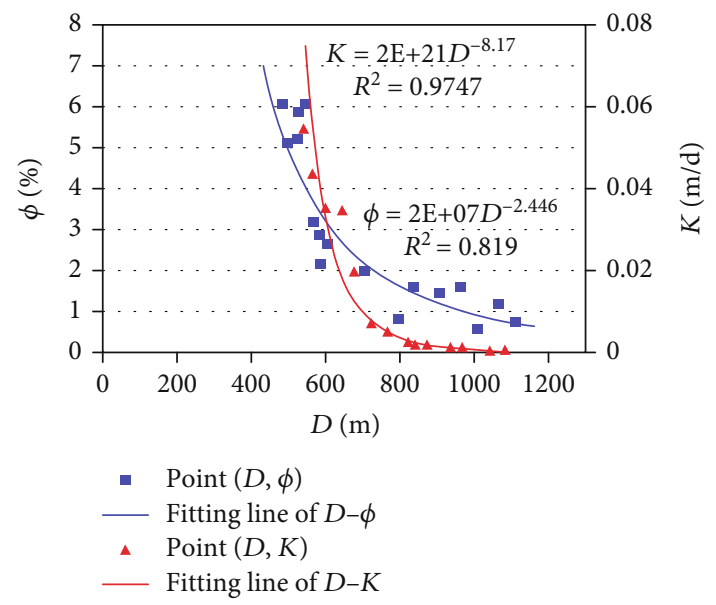

FIgURE 8: Changes in the porosity $(\oint)$ and permeability $(K)$ of aquifers with changing depth $(D)$.

before or after mining, respectively. The water-pressure variation and water runoff in the aquifer after mining are shown in Figure 11. The persistence of $P_{b}$ is assured by the continuous flow of water into the cavity. The efficiency of the water movement in the aquifer is related to the water yield of the aquifer. Obviously, a lower water yield in the confined aquifer results in lower efficiency of the seepage flow to the cavity, slower deformation in the aquiclude, longer time for the aquiclude to deform to its breaking state, greater possibility for $t_{r}$ to exceed $t_{a}$, and less possibility of water inrush. The water yield of aquifers is often described in terms of $q$. In other words, the smaller the $q$ value, the lower the possibility of water inrush.

For water inrush caused by dangerous geological structures (i.e., faults, collapse columns, etc.), the initiation process involves erosion of the filler in the cracks of these structures owing to water flow, which is also caused by the continuity of seepage. Similar to the water inrush in the 


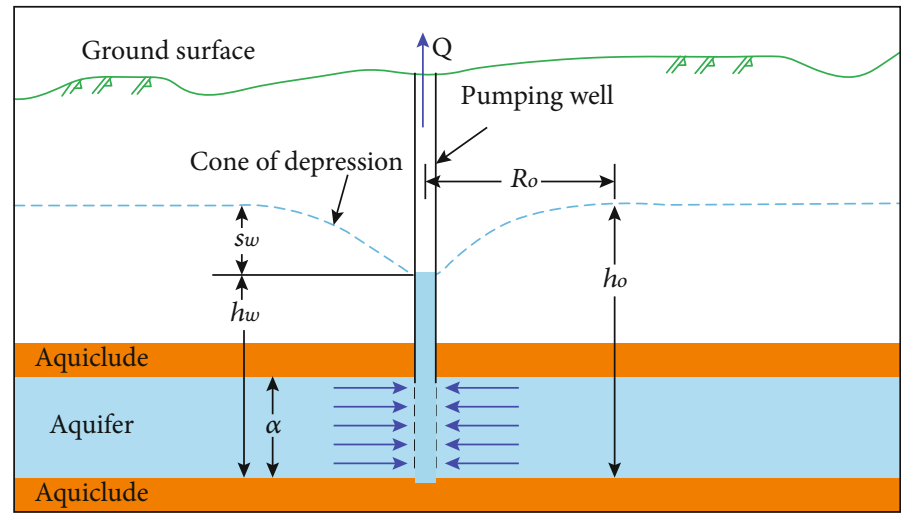

FIGURE 9: Pumping test of a steady well flow in a confined aquifer.

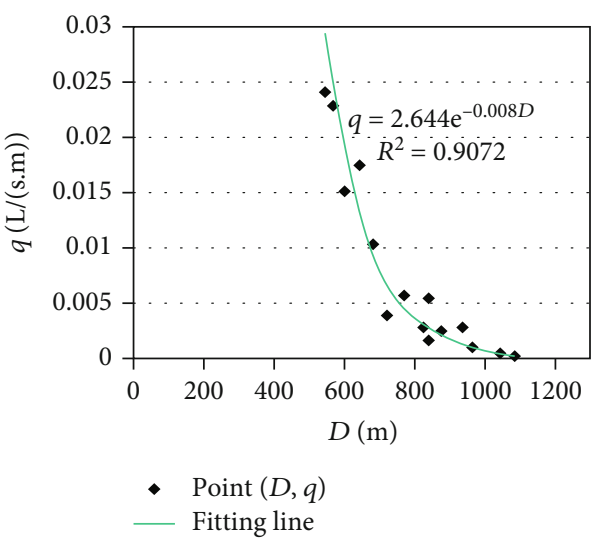

Figure 10: Change in the specific yield $(q)$ for different depths $(D)$.

cavity described earlier, the smaller the $q$, the lower is the possibility of water inrush in the dangerous geological structures.

3.2. After Formation of Water Inrush. Water inrush data from 186 excavation faces in the North China coalfield (Tables 2-4) were collected to analyze the role of $q$ in the water inrush.

Usually, according to the volume of water inflow (Q) recorded in each case, water inrush is classified as a small case $\left(0<Q \leq 60 \mathrm{~m}^{3} / \mathrm{h}\right)$, medium case $\left(60<Q<600 \mathrm{~m}^{3} / \mathrm{h}\right)$, or large case $\left(Q \geq 600 \mathrm{~m}^{3} / \mathrm{h}\right)$. Among the 186 water inrush cases studied, 79 were small, 95 were medium, and 12 were large.

The statistical summary of the 186 water inrush cases (Table 5) shows that almost all the small- $Q$ cases were located in areas with $0.06 \leq q<1.7 \mathrm{~L} /(\mathrm{s} \cdot \mathrm{m})$, almost all the medium$Q$ cases were located in areas with $1.7 \leq q<16.7 \mathrm{~L} /(\mathrm{s} \cdot \mathrm{m})$, and all the large- $Q$ cases were located in areas with $q \geq 16.7$ $\mathrm{L} /(\mathrm{s} \cdot \mathrm{m})$. No water inrush cases occurred when $q<0.06 \mathrm{~L}$ $/(\mathrm{s} \cdot \mathrm{m})$.

After a water inrush occurs, the larger the value of $q$, the greater the amount of water poured out because of the greater water yield of the aquifer, the larger the amount of water released from the aquifer in a short period, and the larger the amount of water that flows into the mining area. Therefore, $q$ can determine the magnitude of the water inrush after an event.

\section{Establishment and Application of the $T-q$ Method}

In this section, the development of a convenient method for water inrush risk assessment that considers $q$ is discussed.

A confined aquifer is a source of power and the medium for the water inrush. An aquiclude is the medium that can obstruct water inrush. Water inrush is related not only to the potential of the confined water to break through the aquiclude but also to the extent of release of this potential (unless otherwise stated, this is the potential referred to hereafter). $P$ and $M$ parametrize the potential of the confined water to break through the aquiclude, and $q$ is a nonnegligible parameter that determines the extent of this potential release. The contributions of these parameters to the possibility of water inrush are described below.

First, when $P$ is big and $M$ is small, the potential for water inrush is high. Therefore, the ratio of $P$ to $M$ (i.e., $T$ ) can be used to indicate the potential for water inrush. The greater the value of $T$, the higher the potential for water inrush. Second, the greater the value of $q$, the better the hydrodynamic conditions in the aquifer, the greater the extent of this potential release, and the higher the possibility of water inrush. Therefore, the possibility of water inrush is positively correlated with both $T$ and $q$ values.

4.1. Division of Water Inrush and Safety Zones in the T-q Method. From the previous analysis, the possibility of water inrush was determined in terms of $T$ and $q$. When the potential for water inrush is greater, the energy that can be directly applied to break through the aquiclude or the water inrush channels is larger and the possibility of water inrush is greater. In other words, for constant $q$, the greater the value of $T$, the higher the possibility of water inrush. Figure 12 shows the 186 water inrush cases used to obtain the $T_{s}-q$ function curve. Because $T_{s}$ is the minimum $T$ that can initiate occurrence of water inrush, the $T_{s}$ points should be in the area where $T$ is relatively small for a certain $q$ value of the aquifer. The points marked by the symbol " $x$ " in Figure 12 were selected as the critical points, and the $T_{s}-q$ function curve was obtained by fitting these points. The points in the area above the $T_{s}-q$ curve were identified as the water inrush points, and those in the area below the $T_{s}-q$ curve were the 
Table 1: Mining cases in the North China coalfield, wrongly evaluated by the $T$ method.

\begin{tabular}{|c|c|c|c|c|c|c|c|}
\hline No. & Mining face & $\begin{array}{c}P \\
(\mathrm{MPa})\end{array}$ & $\begin{array}{c}q \\
(\mathrm{~L} /(\mathrm{s} \cdot \mathrm{m}))\end{array}$ & $\begin{array}{c}T \\
(\mathrm{MPa} / \mathrm{m})\end{array}$ & $\begin{array}{c}T_{s} \\
(\mathrm{MPa} / \mathrm{m})\end{array}$ & $\begin{array}{l}\text { Evaluation } \\
\text { results }\end{array}$ & Field verification \\
\hline 1 & $\begin{array}{l}\text { III628, Zhuzhuang mine, Huaibei mining } \\
\text { area }\end{array}$ & 4.22 & 0.016 & 0.140 & 0.07 & Danger & Safety \\
\hline 2 & $\begin{array}{l}\text { III616, Yangzhuang mine, Huaibei mining } \\
\text { area }\end{array}$ & 5.50 & 0.052 & 0.110 & 0.07 & Danger & Safety \\
\hline 3 & 1044, Liudian mine, Huaibei mining area & 6.93 & 0.024 & 0.210 & 0.07 & Danger & Safety \\
\hline 4 & 1037, Liudian mine, Huaibei mining area & 6.60 & 0.024 & 0.330 & 0.07 & Danger & Safety \\
\hline 5 & 1088, Heishan mine, Zibo mining area & 6.23 & 0.032 & 0.130 & 0.07 & Danger & Safety \\
\hline 6 & 11022, Jiulishan mine, Jiaozuo mining area & 1.19 & 24.450 & 0.052 & 0.07 & Safety & Danger, $Q=714 \mathrm{~m}^{3} / \mathrm{h}$ \\
\hline 7 & $\begin{array}{l}\text { 9507, Xiangzhuang mine, Feicheng mining } \\
\text { area }\end{array}$ & 0.92 & 8.330 & 0.038 & 0.07 & Safety & Danger, $Q=300 \mathrm{~m}^{3} / \mathrm{h}$ \\
\hline 8 & 4221, Jiaoxi mine, Jiaozuo mining area & 1.00 & 12.620 & 0.053 & 0.07 & Safety & Danger, $Q=201 \mathrm{~m}^{3} / \mathrm{h}$ \\
\hline 9 & 12031, Jiulishan mine, Jiaozuo mining area & 0.92 & 11.330 & 0.041 & 0.07 & Safety & Danger, $Q=588 \mathrm{~m}^{3} / \mathrm{h}$ \\
\hline 10 & 1007, Fucun mine, Zibo mining area & 1.46 & 7.120 & 0.043 & 0.07 & Safety & Danger, $Q=256 \mathrm{~m}^{3} / \mathrm{h}$ \\
\hline
\end{tabular}

Note: $Q$ refers to the water inflow in a water inrush case.

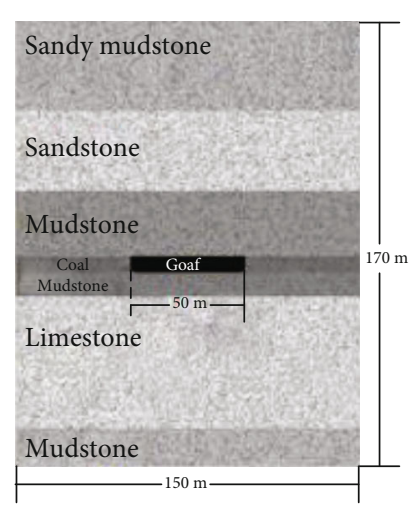

(a)

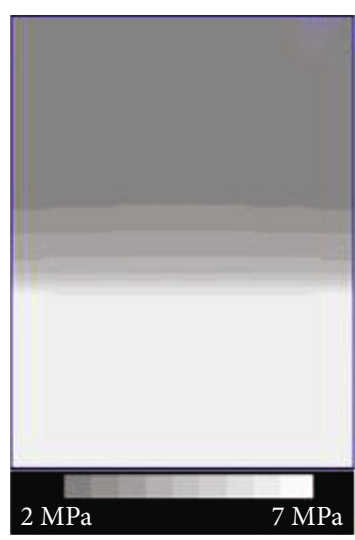

(b)

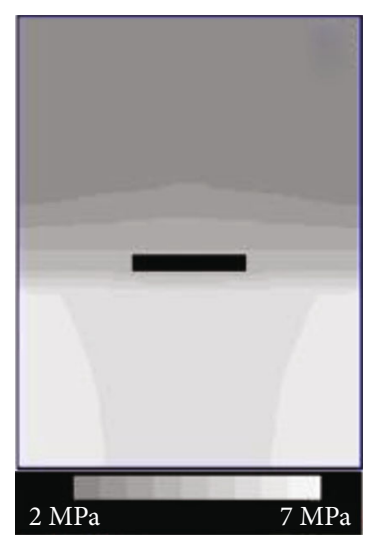

(c)

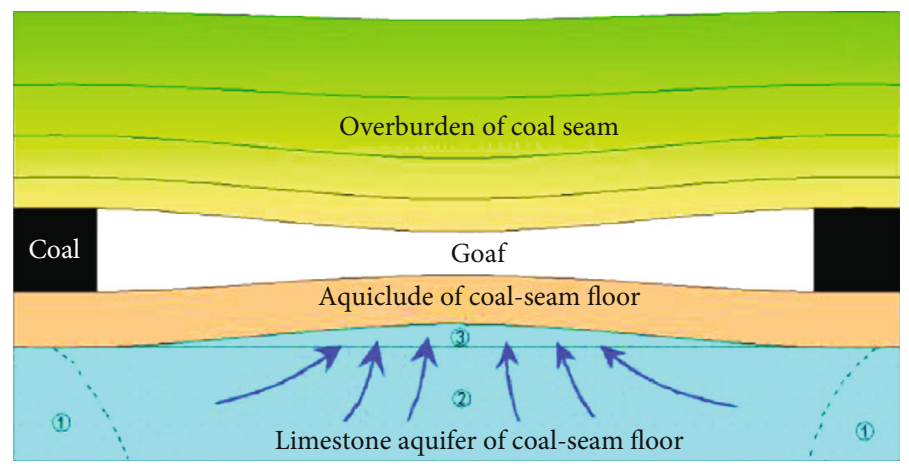

(d)

FIGURE 11: Definition of terms used for risk assessment of water inrush from the coal-seam floor. (a) Numerical model designed by RFPA software. (b) Water pressure distribution after self-stable equilibrium of the model before excavation. (c) Water pressure distribution after excavation. (d) Schematic diagram of water migration characteristics in floor aquifer. (1): areas with undisturbed water pressure; (2): area with disturbed water pressure; (3): cavity caused by the deformation of the aquiclude, which is situated between the aquiclude and the aquifer. The blue arrows indicate the water seepage direction.

safety points. Figure 12 shows that except for the fitting points; all the other water inrush points are above the $T_{s}-q$ curve. The water inrush points between the $T_{s}-q$ and the stipulated $T_{s}$ curves were wrongly evaluated as safety points by the $T$ method, because at these points, $T$ was less than the stipulated $T_{s}$. Therefore, the new method is more practical than the $T$ method in determining the water inrush and safety zones. 
TABLE 2: Specific yield $(q)$ and water inrush coefficient $(T)$ values in small water inrush cases.

\begin{tabular}{lccccccccc}
\hline$q(\mathrm{~L} /(\mathrm{s} \cdot \mathrm{m}))$ & $T(\mathrm{MPa} / \mathrm{m})$ & $q(\mathrm{~L} /(\mathrm{s} \cdot \mathrm{m}))$ & $T(\mathrm{MPa} / \mathrm{m})$ & $q(\mathrm{~L} /(\mathrm{s} \cdot \mathrm{m}))$ & $T(\mathrm{MPa} / \mathrm{m})$ & $q(\mathrm{~L} /(\mathrm{s} \cdot \mathrm{m}))$ & $T(\mathrm{MPa} / \mathrm{m})$ & $q(\mathrm{~L} /(\mathrm{s} \cdot \mathrm{m}))$ & $T(\mathrm{MPa} / \mathrm{m})$ \\
\hline 1.667 & 0.024 & 1.333 & 0.025 & 0.167 & 0.108 & 0.583 & 0.068 & 1.417 \\
1.167 & 0.030 & 1.117 & 0.045 & 1.167 & 0.052 & 0.955 & 0.042 & 0.333 \\
1.333 & 0.056 & 0.167 & 0.047 & 1.300 & 0.037 & 1.000 & 0.057 & 1.628 & 0.070 \\
1.167 & 0.040 & 1.210 & 0.168 & 0.333 & 0.052 & 1.333 & 0.057 & 1.117 \\
0.733 & 0.089 & 1.650 & 0.047 & 1.333 & 0.082 & 0.417 & 0.062 & 1.250 \\
1.000 & 0.051 & 0.167 & 0.092 & 0.860 & 0.058 & 0.083 & 0.058 & 1.580 & 0.089 \\
1.450 & 0.054 & 1.033 & 0.108 & 0.667 & 0.162 & 1.667 & 0.060 & 0.767 \\
0.717 & 0.063 & 0.083 & 0.114 & 0.443 & 0.065 & 0.700 & 0.055 & 0.500 \\
1.667 & 0.018 & 0.167 & 0.161 & 1.133 & 0.059 & 0.443 & 0.077 & 0.500 \\
1.167 & 0.057 & 0.667 & 0.161 & 0.500 & 0.166 & 1.312 & 0.069 & 1.333 \\
1.167 & 0.047 & 0.500 & 0.170 & 0.500 & 0.046 & 1.210 & 0.083 & 1.417 \\
0.833 & 0.046 & 0.500 & 0.182 & 0.333 & 0.027 & 0.443 & 0.072 & 0.052 \\
2.000 & 0.191 & 0.083 & 0.052 & 0.390 & 0.079 & 0.067 & 0.073 & 0.043 \\
1.333 & 0.038 & 1.018 & 0.067 & 0.583 & 0.061 & 0.125 & 0.105 & 0.053 \\
0.500 & 0.037 & 0.083 & 0.101 & 1.697 & 0.056 & 0.167 & 0.060 & 0.069 \\
1.667 & 0.038 & 0.333 & 0.085 & 0.390 & 0.078 & 1.000 & 0.072 & 0.045 \\
\hline
\end{tabular}

TABLE 3: Specific yield $(q)$ and water inrush coefficient $(T)$ values in medium water inrush cases.

\begin{tabular}{|c|c|c|c|c|c|c|c|c|c|}
\hline$q(\mathrm{~L} /(\mathrm{s} \cdot \mathrm{m}))$ & $T(\mathrm{MPa} / \mathrm{m})$ & $q(\mathrm{~L} /(\mathrm{s} \cdot \mathrm{m}))$ & $T(\mathrm{MPa} / \mathrm{m})$ & $q(\mathrm{~L} /(\mathrm{s} \cdot \mathrm{m}))$ & $T(\mathrm{MPa} / \mathrm{m})$ & $q(\mathrm{~L} /(\mathrm{s} \cdot \mathrm{m}))$ & $T(\mathrm{MPa} / \mathrm{m})$ & $q(\mathrm{~L} /(\mathrm{s} \cdot \mathrm{m}))$ & $T(\mathrm{MPa} / \mathrm{m})$ \\
\hline 8.333 & 0.028 & 8.333 & 0.038 & 3.750 & 0.051 & 2.450 & 0.052 & 5.882 & 0.071 \\
\hline 12.500 & 0.018 & 10.000 & 0.046 & 0.867 & 0.057 & 4.000 & 0.036 & 6.147 & 0.065 \\
\hline 11.00 & 0.024 & 11.500 & 0.043 & 12.833 & 0.074 & 11.667 & 0.046 & 4.578 & 0.054 \\
\hline 4.000 & 0.017 & 2.500 & 0.076 & 1.783 & 0.068 & 9.167 & 0.048 & 6.378 & 0.051 \\
\hline 4.667 & 0.018 & 10.417 & 0.022 & 2.533 & 0.052 & 3.333 & 0.059 & 2.167 & 0.060 \\
\hline 11.000 & 0.016 & 12.617 & 0.053 & 10.55 & 0.061 & 2.663 & 0.059 & 3.883 & 0.068 \\
\hline 13.000 & 0.018 & 7.167 & 0.074 & 4.167 & 0.051 & 5.000 & 0.049 & 2.717 & 0.043 \\
\hline 14.167 & 0.043 & 8.833 & 0.034 & 11.333 & 0.041 & 3.333 & 0.021 & 9.167 & 0.075 \\
\hline 3.333 & 0.015 & 3.053 & 0.079 & 3.467 & 0.056 & 10.000 & 0.096 & 5.000 & 0.062 \\
\hline 5.167 & 0.026 & 9.633 & 0.056 & 15.500 & 0.069 & 10.000 & 0.052 & 2.500 & 0.026 \\
\hline 8.333 & 0.023 & 7.600 & 0.065 & 6.667 & 0.012 & 7.117 & 0.043 & 2.667 & 0.078 \\
\hline 13.333 & 0.018 & 3.333 & 0.039 & 4.533 & 0.176 & 10.750 & 0.052 & 11.700 & 0.034 \\
\hline 5.000 & 0.044 & 5.583 & 0.083 & 9.733 & 0.064 & 6.667 & 0.024 & 5.417 & 0.087 \\
\hline 3.333 & 0.026 & 2.533 & 0.061 & 4.033 & 0.072 & 3.333 & 0.043 & 3.667 & 0.086 \\
\hline 4.667 & 0.021 & 2.167 & 0.085 & 1.833 & 0.041 & 2.500 & 0.055 & 4.333 & 0.085 \\
\hline 8.333 & 0.021 & 2.767 & 0.077 & 3.783 & 0.031 & 4.333 & 0.053 & 6.167 & 0.097 \\
\hline 16.667 & 0.013 & 4.167 & 0.046 & 2.283 & 0.037 & 6.250 & 0.070 & 3.000 & 0.091 \\
\hline 13.333 & 0.022 & 2.00 & 0.045 & 5.417 & 0.025 & 3.543 & 0.167 & 9.500 & 0.091 \\
\hline 8.333 & 0.024 & 4.00 & 0.128 & 4.833 & 0.026 & 2.417 & 0.069 & 4.000 & 0.085 \\
\hline
\end{tabular}

TABLE 4: Specific yield $(q)$ and water inrush coefficient $(T)$ values in large water inrush cases.

\begin{tabular}{lccccccc}
\hline$q(\mathrm{~L} /(\mathrm{s} \cdot \mathrm{m}))$ & $T(\mathrm{MPa} / \mathrm{m})$ & $q(\mathrm{~L} /(\mathrm{s} \cdot \mathrm{m}))$ & $T(\mathrm{MPa} / \mathrm{m})$ & $q(\mathrm{~L} /(\mathrm{s} \cdot \mathrm{m}))$ & $T(\mathrm{MPa} / \mathrm{m})$ & $q(\mathrm{~L} /(\mathrm{s} \cdot \mathrm{m}))$ & $T(\mathrm{MPa} / \mathrm{m})$ \\
\hline 20.000 & 0.050 & 28.000 & 0.011 & 21.667 & 0.049 & 24.333 \\
19.283 & 0.052 & 24.450 & 0.052 & 19.817 & 0.037 & 20.667 & 0.057 \\
16.700 & 0.028 & 25.000 & 0.041 & 23.183 & 0.075 & 17.067 & 0.067 \\
\hline
\end{tabular}


TABLE 5: Number of water inrush cases for each volume of water inflow $(Q)$ and different magnitudes of specific yield $(q)$.

\begin{tabular}{lccc}
\hline Magnitude of $q(\mathrm{~L} /(\mathrm{s} \cdot \mathrm{m}))$ & Small-Q water inrush cases & $\begin{array}{c}\text { Number of water inrush cases } \\
\text { Medium- } Q \text { water inrush cases }\end{array}$ & \begin{tabular}{c} 
Large- $Q$ water inrush cases \\
\hline$q<0.06$
\end{tabular} $0^{-0}$ \\
$0.06 q<1.7$ & 78 & 0 & 0 \\
$1.7 \leq q<16.7$ & 1 & 94 & 0 \\
$q \geq 16.7$ & 0 & 0 & 12 \\
\hline
\end{tabular}

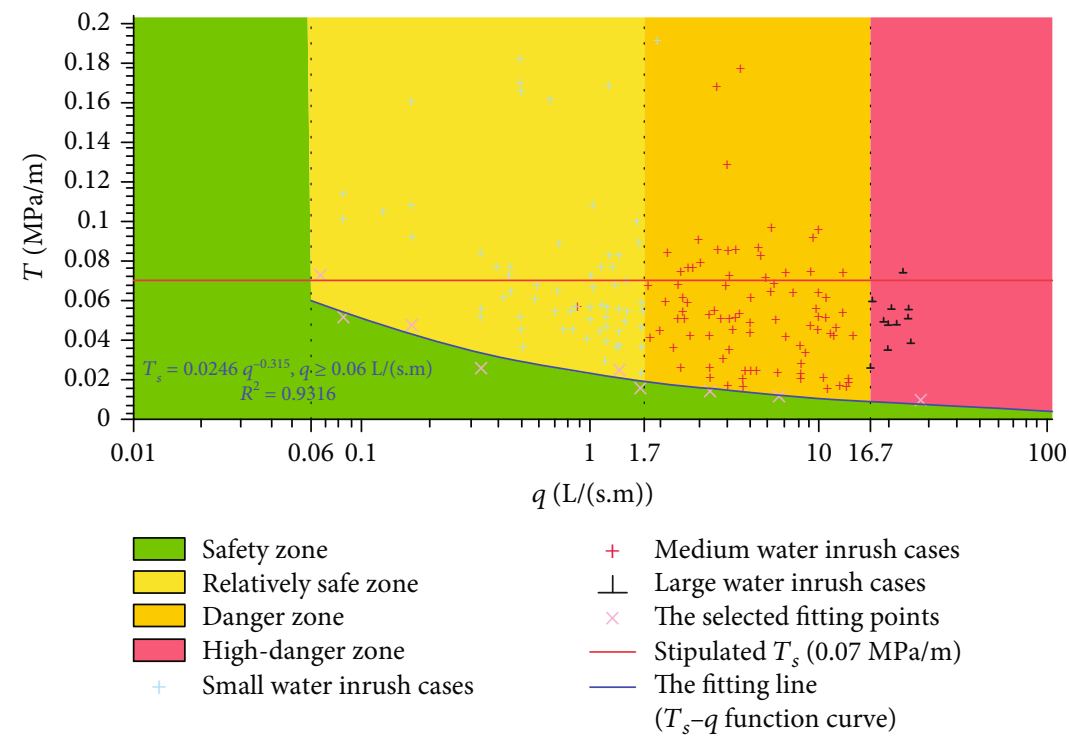

FIGURE 12: Discrimination diagram using the $T$ - $q$ method.

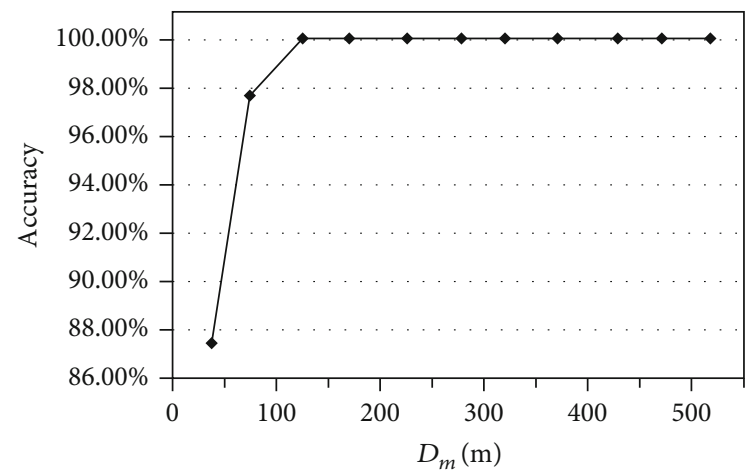

FIGURE 13: Change in the accuracy of the prediction with different mining depths $\left(D_{m}\right)$ using the $T$ - $q$ method.

The $T_{s}-q$ curve also shows that $T_{s}$ is not fixed but changes with changing $q$. There is a negative correlation between $T_{s}$ and $q$. The relationship between them is expressed as follows:

$$
T_{s}=0.0246 q^{-0.315}, q \geq 0.06 \mathrm{~L} /(\mathrm{s} \cdot \mathrm{m})
$$

The areas below and above the $T_{s}-q$ curve were defined as the safety and water inrush zones, respectively.

The list in Table 5 indicates that no water inrush accidents occurred when $q<0.06 \mathrm{~L} /(\mathrm{s} \cdot \mathrm{m})$. Therefore, the line at $q=0.06 \mathrm{~L} /(\mathrm{s} \cdot \mathrm{m})$ can also be used as the division between the water inrush and safety zones, considering that the area with $q<0.06 \mathrm{~L} /(\mathrm{s} \cdot \mathrm{m})$ is the safety zone. In this interval, $T_{s}$ was not affected by $q$. A larger but not definitive value could be considered as the value of $T_{s}$, which is represented by the symbol $\infty$.

$$
T_{s}=\infty, q<0.06 \mathrm{~L} /(\mathrm{s} \cdot \mathrm{m})
$$

4.2. Risk Level Classification in Water Inrush Zone in the T-q Method. For the area above the $T_{s}-q$ curve, the risk level was determined by the value of $q$ in the aquifer.

Table 5 and Figure 12 show that the boundary between the small and medium water inrush cases was $q=1.7 \mathrm{~L} /(\mathrm{s}$. $\mathrm{m})$. The area where the small water inrush cases were distributed was defined as a relatively safe zone because $Q$ in these cases was sufficiently small to be easily drained and could not affect mine production. The boundary between the medium and large water inrush cases was $q=16.7 \mathrm{~L} /(\mathrm{s} \cdot \mathrm{m})$. The area where the medium water inrush cases were distributed was defined as a danger zone because $Q$ was relatively large and would have a negative influence on mine production. Applying the same logic, the area where the large water inrush cases were distributed was called a high-danger zone because $Q$ was too large for rapid draining and would jeopardize safe mine production. 
TABLE 6: Application cases in the North China coalfield evaluated by the $T$ - $q$ method.

\begin{tabular}{|c|c|c|c|c|c|c|c|c|}
\hline No. & Mining face & $\begin{array}{l}D_{m} \\
(\mathrm{~m})\end{array}$ & $\begin{array}{c}P \\
(\mathrm{MPa})\end{array}$ & $\begin{array}{c}q \\
(\mathrm{~L} /(\mathrm{s} \cdot \mathrm{m}))\end{array}$ & $\begin{array}{c}T \\
(\mathrm{MPa} / \mathrm{m})\end{array}$ & $\begin{array}{c}T_{s} \\
(\mathrm{MPa} / \mathrm{m})\end{array}$ & Evaluation results & Field verification \\
\hline A & $\begin{array}{l}\text { III628, Zhuzhuang mine, } \\
\text { Huaibei mining area }\end{array}$ & 408.47 & 4.22 & 0.016 & 0.140 & $\infty$ & Safety & Safety \\
\hline B & $\begin{array}{l}\text { III616, Yangzhuang mine, } \\
\text { Huaibei mining area }\end{array}$ & 518.25 & 5.50 & 0.052 & 0.110 & $\infty$ & Safety & Safety \\
\hline $\mathrm{C}$ & $\begin{array}{l}\text { 1044, Liudian mine, Huaibei } \\
\text { mining area }\end{array}$ & 680.08 & 6.93 & 0.024 & 0.210 & $\infty$ & Safety & Safety \\
\hline $\mathrm{D}$ & $\begin{array}{l}\text { 1037, Liudian mine, Huaibei } \\
\text { mining area }\end{array}$ & 659.66 & 6.60 & 0.024 & 0.330 & $\infty$ & Safety & Safety \\
\hline $\mathrm{E}$ & $\begin{array}{l}\text { 1088, Heishan mine, Zibo } \\
\text { mining area }\end{array}$ & 594.26 & 6.23 & 0.032 & 0.130 & $\infty$ & Safety & Safety \\
\hline $\mathrm{F}$ & $\begin{array}{l}\text { 11022, Jiulishan mine, } \\
\text { Jiaozuo mining area }\end{array}$ & 108.85 & 1.19 & 24.450 & 0.052 & 0.0090 & $\begin{array}{c}\text { Water inrush with } Q \geq 600 \mathrm{~m}^{3} \\
/ \mathrm{h} \text { (high danger) }\end{array}$ & $\begin{array}{l}\text { Water inrush with } \\
\qquad Q=714 \mathrm{~m}^{3} / \mathrm{h}\end{array}$ \\
\hline G & $\begin{array}{l}\text { 9507, Xiangzhuang mine, } \\
\text { Feicheng mining area }\end{array}$ & 80.18 & 0.92 & 8.330 & 0.038 & 0.0126 & $\begin{array}{l}\text { Water inrush with } 60<Q< \\
\quad 600 \mathrm{~m}^{3} / \mathrm{h} \text { (danger) }\end{array}$ & $\begin{array}{l}\text { Water inrush with } \\
\qquad Q=300 \mathrm{~m}^{3} / \mathrm{h}\end{array}$ \\
\hline $\mathrm{H}$ & $\begin{array}{l}\text { 4221, Jiaoxi mine, Jiaozuo } \\
\text { mining area }\end{array}$ & 93.62 & 1.00 & 12.620 & 0.053 & 0.0111 & $\begin{array}{l}\text { Water inrush with } 60<Q< \\
600 \mathrm{~m}^{3} / \mathrm{h} \text { (danger) }\end{array}$ & $\begin{array}{l}\text { Water inrush with } \\
\qquad Q=201 \mathrm{~m}^{3} / \mathrm{h}\end{array}$ \\
\hline I & $\begin{array}{l}\text { 12031, Jiulishan mine, } \\
\text { Jiaozuo mining area }\end{array}$ & 81.95 & 0.92 & 11.330 & 0.041 & 0.0115 & $\begin{array}{l}\text { Water inrush with } 60<Q< \\
\quad 600 \mathrm{~m}^{3} / \mathrm{h} \text { (danger) }\end{array}$ & $\begin{array}{l}\text { Water inrush with } \\
\qquad Q=588 \mathrm{~m}^{3} / \mathrm{h}\end{array}$ \\
\hline $\mathrm{J}$ & $\begin{array}{l}\text { 1007, Fucun mine, Zibo } \\
\text { mining area }\end{array}$ & 125.13 & 1.46 & 7.120 & 0.043 & 0.0133 & $\begin{array}{l}\text { Water inrush with } 60<Q< \\
\quad 600 \mathrm{~m}^{3} / \mathrm{h} \text { (danger) }\end{array}$ & $\begin{array}{l}\text { Water inrush with } \\
\qquad Q=256 \mathrm{~m}^{3} / \mathrm{h}\end{array}$ \\
\hline K & $\begin{array}{l}\text { 4231, Jiaoxi mine, Jiaozuo } \\
\text { mining area }\end{array}$ & 109.88 & 1.17 & 3.33 & 0.059 & 0.0168 & $\begin{array}{l}\text { Water inrush with } 60<Q< \\
\quad 600 \mathrm{~m}^{3} / \mathrm{h} \text { (danger) }\end{array}$ & $\begin{array}{l}\text { Water inrush with } \\
\qquad Q=91 \mathrm{~m}^{3} / \mathrm{h}\end{array}$ \\
\hline $\mathrm{L}$ & $\begin{array}{l}\text { 9304, Shida mine, Zibo } \\
\text { mining area }\end{array}$ & 182.12 & 1.96 & 5.88 & 0.071 & 0.0141 & $\begin{array}{l}\text { Water inrush with } 60<Q< \\
\quad 600 \mathrm{~m}^{3} / \mathrm{h} \text { (danger) }\end{array}$ & $\begin{array}{l}\text { Water inrush with } \\
\qquad Q=210 \mathrm{~m}^{3} / \mathrm{h}\end{array}$ \\
\hline M & $\begin{array}{l}\text { 10401, Taoyang mine, } \\
\text { Feicheng mining area }\end{array}$ & 43.40 & 0.54 & 1.67 & 0.024 & 0.0209 & $\begin{array}{c}\text { Water inrush with } 0<Q \leq 60 \\
\mathrm{~m}^{3} / \mathrm{h} \text { (relatively safe) }\end{array}$ & $\begin{array}{l}\text { Water inrush with } \\
\qquad Q=60 \mathrm{~m}^{3} / \mathrm{h}\end{array}$ \\
\hline $\mathrm{N}$ & $\begin{array}{l}\text { 42013, Jiaoxi mine, Jiaozuo } \\
\text { mining area }\end{array}$ & 72.24 & 0.8 & 1.17 & 0.04 & 0.0234 & $\begin{array}{c}\text { Water inrush with } 0<Q \leq 60 \\
\mathrm{~m}^{3} / \mathrm{h} \text { (relatively safe) }\end{array}$ & $\begin{array}{l}\text { Water inrush with } \\
\qquad Q=42 \mathrm{~m}^{3} / \mathrm{h}\end{array}$ \\
\hline $\mathrm{O}$ & $\begin{array}{l}\text { 11051, Jiulishan mine, } \\
\text { Jiaozuo mining area }\end{array}$ & 139.32 & 1.5 & 0.72 & 0.063 & 0.0273 & $\begin{array}{c}\text { Water inrush with } 0<Q \leq 60 \\
\mathrm{~m}^{3} / \mathrm{h} \text { (relatively safe) }\end{array}$ & $\begin{array}{l}\text { Water inrush with } \\
\qquad Q=26 \mathrm{~m}^{3} / \mathrm{h}\end{array}$ \\
\hline $\mathrm{P}$ & $\begin{array}{l}\text { 9301, Shida mine, Zibo } \\
\text { mining area }\end{array}$ & 225.28 & 2.42 & 0.39 & 0.078 & 0.0331 & $\begin{array}{c}\text { Water inrush with } 0<Q \leq 60 \\
\mathrm{~m}^{3} / \mathrm{h} \text { (relatively safe) }\end{array}$ & $\begin{array}{l}\text { Water inrush with } \\
\qquad Q=14 \mathrm{~m}^{3} / \mathrm{h}\end{array}$ \\
\hline Q & $\begin{array}{l}\text { 9302, Shida mine, Zibo } \\
\text { mining area }\end{array}$ & 176.57 & 1.91 & 0.58 & 0.068 & 0.0292 & $\begin{array}{c}\text { Water inrush with } 0<Q \leq 60 \\
\mathrm{~m}^{3} / \mathrm{h} \text { (relatively safe) }\end{array}$ & $\begin{array}{l}\text { Water inrush with } \\
\qquad Q=21 \mathrm{~m}^{3} / \mathrm{h}\end{array}$ \\
\hline $\mathrm{R}$ & $\begin{array}{l}\text { 9307, Shida mine, Zibo } \\
\text { mining area }\end{array}$ & 148.54 & 1.64 & 1 & 0.057 & 0.0246 & $\begin{array}{c}\text { Water inrush with } 0<Q \leq 60 \\
\mathrm{~m}^{3} / \mathrm{h} \text { (relatively safe) }\end{array}$ & $\begin{array}{l}\text { Water inrush with } \\
\qquad Q=36 \mathrm{~m}^{3} / \mathrm{h}\end{array}$ \\
\hline S & $\begin{array}{l}\text { 9019, Shida mine, Zibo } \\
\text { mining area }\end{array}$ & 140.63 & 1.54 & 0.08 & 0.058 & 0.0545 & $\begin{array}{c}\text { Water inrush with } 0<Q \leq 60 \\
\mathrm{~m}^{3} / \mathrm{h} \text { (relatively safe) }\end{array}$ & $\begin{array}{l}\text { Water inrush with } \\
\qquad Q=3 \mathrm{~m}^{3} / \mathrm{h}\end{array}$ \\
\hline $\mathrm{T}$ & $\begin{array}{l}\text { 1095, Xiazhuang mine, Zibo } \\
\text { mining area }\end{array}$ & 190.36 & 2.05 & 1 & 0.072 & 0.0246 & $\begin{array}{c}\text { Water inrush with } 0<Q \leq 60 \\
\mathrm{~m}^{3} / \mathrm{h} \text { (relatively safe) }\end{array}$ & $\begin{array}{l}\text { Water inrush with } \\
\qquad Q=36 \mathrm{~m}^{3} / \mathrm{h}\end{array}$ \\
\hline
\end{tabular}

Note: $\infty$ indicates a larger, but not definitive, value of $T_{s}$; the distribution of the cases can be seen in Figure 14 .

4.3. Novelty Analysis of the T-q Method. The abovementioned analysis enabled the development of the $T$ - $q$ method.

Figure 12 shows the discrimination diagram with $T$ on the $y$-axis and $q$ on the $x$-axis. The $T_{s}-q$ curve separates the safety zone from the water inrush zone. The water inrush zone consists of relatively safe, danger, and high-danger zones, which are indicated by different colors. The risk level of the water inrush from the coal-seam floor can be easily and quickly determined by introducing the $q$ and $T$ values of an excavation face onto Figure 12. Thus, the $T-q$ method provides a quick and handy risk assessment in mining. Smaller $q$ indicates lower possibility of water inrush, whereas larger $q$ correlates with higher magnitude of water inrush after the water inrush initiation.

The novelty of this study is reflected in the following two aspects. 


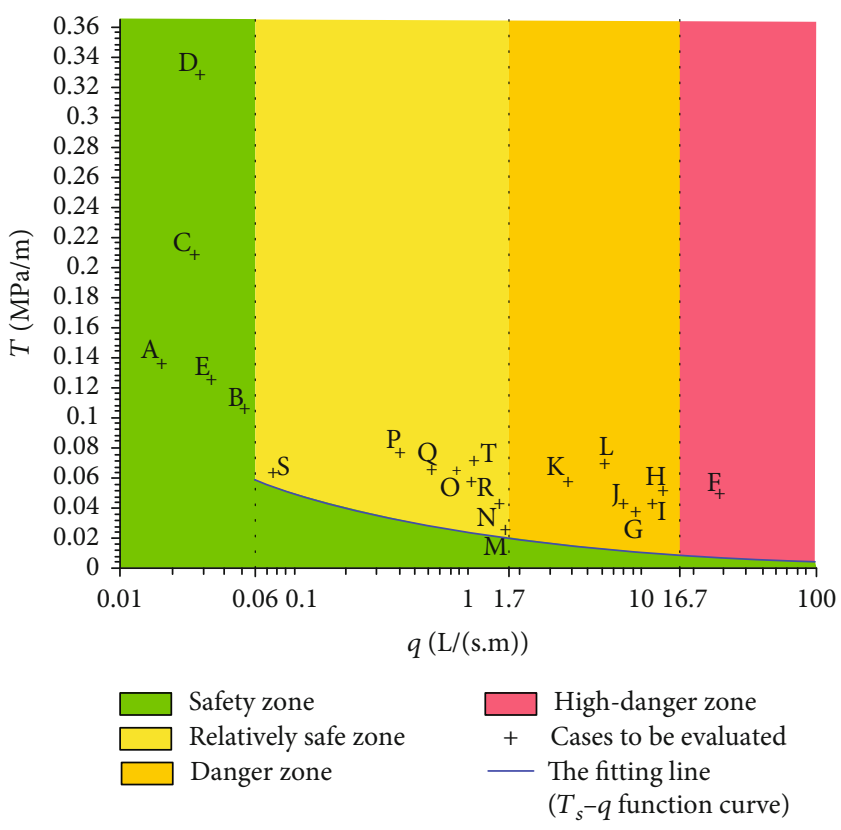

Figure 14: Distribution of application cases recorded in Table 6 in the $T-q$ discrimination diagram.

4.3.1. The T-q Method Is More Accurate and Practical. The occurrence of water inrush actually includes two stages: (1) the formation stage of a water inrush channel and (2) the water-discharge stage from the aquifer into the excavation face. In the formation stage of the water inrush channel, the instability and breakage of the intact aquiclude or dangerous geological structure occur under the action of continuous water pressure. The continuity of water pressure is guaranteed by the water movement in the aquifer. Therefore, when the possibility of water inrush is evaluated, the efficiency of water movement in the aquifer must be considered to obtain more accurate results. In the water-discharge stage from the aquifer to the excavation face, the amount of water inflow into the excavation face is also determined by the efficiency of the water movement in the aquifer. The efficiency of water movement in the aquifer is related to $q$. Therefore, the $q$ of the aquifers that recharge the mine must be considered to accurately assess the water inrush risk. Compared with the traditional $T$ method, the $T-q$ method proposed herein provides a more realistic risk assessment in deep mining because $q$ is considered.

As it can be seen from Figure 13, the method proposed in this paper has high accuracy for different $D_{m}$. The accuracy is generally higher than $80 \%$. Given that the results of this paper were obtained through the statistical analysis of the existing sample data, the accuracy of the method will inevitably be affected by the number of samples and the distribution range of the $D_{m}$ of the samples. If we get a large number of sample data with different $D_{m}$, the accuracy of the method will increase. Although the accuracy of the method is affected by the number of samples, the conclusion stating that the accuracy of the method is higher than that of the $T$ method is convincing because $T_{s}$ is treated as a $q$-related variable. Especially when the mining depth is very shallow or deep, the accuracy of the method is higher than that of the $T$ method.
4.3.2. The T-q Method Is Simple and Can Be Quickly Used. Many factors related to water inrush exist, including the size of the excavation face, $D_{m}$, and complexity of the geological structure. Therefore, as more factors are considered in the evaluation of water inrush risk, more accurate are the evaluation results. However, considering more factors involves a more complex analysis and calculation, which can make difficult its application. Therefore, the selection of the most decisive factors needs to consider both the accuracy of the results and the simplicity of the discrimination process. Several decades of mining practice have proven that the results of the water inrush risk assessment based solely on the size of $P, M$, and $q$ can fully provide a guide to the prevention and control of mine floods. Compared with the existing multifactor superposition and analytical methods with complex operating process, the proposed method provides a quicker risk assessment in deep mining because only one $T-q$ discrimination diagram is needed to complete the discrimination.

4.4. Application and Verification of the T-q Method. Water inrush cases and safety cases are used to verify the accuracy of the proposed method (Table 6). According to Equations (6) and (7), the $T_{s}$ values of each sampling point in Table 6 can be obtained.

It can be seen from Table 6 that since the $q$ values of points A-E are very small, the $T_{s}$ of points A-E are all $\infty$, which is greater than their actual $T$ values, indicating that water inrush will not occur at these points. The $T_{s}$ values of points $\mathrm{F}-\mathrm{T}$ are smaller than their actual $T$ values, indicating that water inrush will occur at these points. Furthermore, the water quantity range of these water inrush points can be predicted according to the magnitudes of $q$. The actual results show that the risk level of water inrush at all points and the water quantity range of each water inrush point are 
accurately predicted (Figure 14, Table 6). On the contrary, it can be seen from Table 1 that if $q$ is not considered, the water inrush risk of these points will not be predicted accurately. Compared with Tables 1 and 6 , we can conclude that the $T$ $-q$ method is reliable, and $q$ is a key factor that cannot be ignored in water inrush assessment.

\section{Conclusions}

The main contribution of this paper is to improve the $T$ method by obtaining a simple and easy to use method with a higher accuracy. Through this study, the following findings are obtained.

The conventional $T$ method is mostly applicable when $D_{m}$ is about $300 \mathrm{~m}$. The corresponding $T_{s}$ is also extracted based on the prevention and control experience of water disaster in those mines whose $D_{m}$ is about $300 \mathrm{~m}$. The accuracy of the $T$ method is low when $D_{m}$ is very shallow or very deep because in the $T$ method, the $T_{s}$ of different $D_{m}$ is set as a fixed value. Thus, the method neglects the fact that $T_{s}$ is a variable related to $q$, affected by $D_{m}$.

The possibility of water inrush is positively correlated with both $T$ and $q$. $T$ indicates the potential of the confined water to break through the aquiclude, and $q$ is the key parameter that determines the extent of this potential release. The value of the critical $T_{s}$ is not fixed but changes with changing $q$ and has a negative correlation with $q$. The $T$ - $q$ method proposed in this paper has high accuracy for different $D_{m}$, generally being higher than $80 \%$. The risk level of water inrush from the coal seam floor can be easily and quickly determined by introducing the $q$ and $T$ values of an excavation face onto the $T-q$ discrimination diagram. The evaluation results of 20 application cases show that the $T-q$ method has high accuracy at different $D_{m}$.

Compared with the traditional $T$ method and the multifactor superposition analysis method, the method established in this paper has the characteristics of convenient field application and high accuracy. The establishment process of the $T-q$ method can provide reference for the establishment of relevant methods in other coal fields.

\section{Data Availability}

All data used during the study appear in the submitted article are available from the corresponding author upon request.

\section{Conflicts of Interest}

The authors declare that there is no conflict of interest regarding the publication of this paper.

\section{Acknowledgments}

This research was jointly supported by the Project funded by the China Postdoctoral Science Foundation (Grant No. 2019M652015), Fundamental Research Funds for the Central Universities (Grant No. 2017XKZD07), and Natural Science Foundation of China (Grant No. 41772302).

\section{References}

[1] L. Yuan, N. Zhang, J. G. Kan, and Y. Wang, "The concept, model and reserve forecast of green coal resources in China," Journal of China University of Mining and Technology, vol. 47, no. 1, pp. 1-8, 2018.

[2] Q. Wu, Z. L. Zhang, and J. F. Ma, "A new practical methodology of the coal floor water bursting evaluating I: the master controlling index system construction," Journal of China Coal Society, vol. 32, pp. 42-47, 2007.

[3] Q. Wu, Z. L. Zhang, S. Y. Zhang, and J. F. Ma, "A new practical methodology of the coal floor water bursting evaluating II: the vulnerable index method," Journal of China Coal Society, vol. 32, pp. 1121-1126, 2007.

[4] Q. M. Liu and J. W. Hu, "Research on method of waterresisting coefficient for distinguishing floor water inrush danger," Procedia Earth and Planetary Science, vol. 3, pp. 238245, 2011.

[5] Z. P. Meng, G. Q. Li, and X. T. Xie, "A geological assessment method of floor water inrush risk and its application," Engineering Geology, vol. 143-144, pp. 51-60, 2012.

[6] Y. Wang, W. F. Yang, M. Li, and X. Liu, "Risk assessment of floor water inrush in coal mines based on secondary fuzzy comprehensive evaluation," International Journal of Rock Mechanics and Mining Sciences, vol. 52, pp. 50-55, 2012.

[7] J. H. He, W. P. Li, and W. Qiao, "P-H-q evaluation system for risk assessment of water inrush in underground mining in North China coal field, based on rock-breaking theory and water-pressure transmission theory," Geomatics, Natural Hazards and Risk, vol. 9, no. 1, pp. 524-543, 2018.

[8] H. F. Duan, Z. Q. Jiang, S. Y. Zhu, L. J. Zhao, and J. G. Liu, "A expansive limits anti-permeability strength methodology of the coal mine floor water inrush evaluating," Procedia Environmental Sciences, vol. 12, pp. 372-378, 2012.

[9] H. B. Bai, D. Ma, and Z. Q. Chen, "Mechanical behavior of groundwater seepage in karst collapse pillars," Engineering Geology, vol. 164, pp. 101-106, 2013.

[10] L. W. Chen, X. Q. Feng, W. P. Xie, and D. Q. Xu, "Prediction of water-inrush risk areas in process of mining under the unconsolidated and confined aquifer: a case study from the Qidong coal mine in China," Environment and Earth Science, vol. 75, no. $8,2016$.

[11] S. C. Zhang, W. J. Guo, and Y. Y. Li, "Experimental simulation of water-inrush disaster from the floor of mine and its mechanism investigation," Arabian Journal of Geosciences, vol. 10, no. 22, pp. 502-512, 2017.

[12] R. Gao, H. Yan, F. Ju, X. C. Mei, and X. L. Wang, "Influential factors and control of water inrush in a coal seam as the main aquifer," International Journal of Mining Science and Technology, vol. 28, no. 2, pp. 187-193, 2018.

[13] W. H. Shi and T. H. Yang, "A coupled nonlinear flow model for particle migration and seepage properties of water inrush through broken rock mass," Geofluids, vol. 2020, Article ID 1230542, 14 pages, 2020.

[14] T. Li, T. T. Mei, X. H. Sun, Y. G. Lv, J. Q. Sheng, and M. Cai, "A study on a water-inrush incident at Laohutai coalmine," International Journal of Rock Mechanics and Mining Sciences, vol. 59, pp. 151-159, 2013.

[15] Q. S. Bai, S. H. Tu, C. Zhang, and D. F. Zhu, "Discrete element modeling of progressive failure in a wide coal roadway from water-rich roofs," International Journal of Coal Geology, vol. 167, pp. 215-229, 2016. 
[16] B. Li and Y. L. Chen, "Risk assessment of coal floor water inrush from underlying aquifers based on GRA-AHP and its application," Geotechnical and Geological Engineering, vol. 34, no. 1, pp. 143-154, 2016.

[17] J. S. Wu, S. D. Xu, R. Zhou, and Y. P. Qin, "Scenario analysis of mine water inrush hazard using Bayesian networks," Safety Science, vol. 89, pp. 231-239, 2016.

[18] S. L. Liu, W. T. Liu, and J. J. Shen, "Stress evolution law and failure characteristics of mining floor rock mass above confined water," KSCE Journal of Civil Engineering, vol. 21, no. 7, pp. 2665-2672, 2017.

[19] M. Qiu, L. Q. Shi, C. Teng, and Y. Zhou, “Assessment of water inrush risk using the fuzzy Delphi analytic hierarchy process and grey relational analysis in the Liangzhuang coal mine, China," Mine Water and the Environment, vol. 36, no. 1, pp. 39-50, 2017.

[20] L. Q. Shi, W. F. Gao, J. Han, and X. P. Tan, "A nonlinear risk evaluation method for water inrush through the seam floor," Mine Water and the Environment, vol. 36, no. 4, pp. 597605, 2017.

[21] B. B. Yang, W. H. Sui, and L. H. Duan, "Risk assessment of water inrush in an underground coal mine based on GIS and fuzzy set theory," Mine Water and the Environment, vol. 36, no. 4, pp. 617-627, 2017.

[22] B. Y. Yu, Z. Q. Chen, J. Y. Wu, and L. Z. Wang, "Experimental study of non-Darcy flow seepage properties of cemented broken rocks with mass loss," Journal of China University of Mining and Technology, vol. 46, pp. 321-327, 2017.

[23] G. L. Dai, X. Y. Xue, K. Xu, L. Dong, and C. Niu, “A GISbased method of risk assessment on no. 11 coal-floor water inrush from Ordovician limestone in Hancheng mining area, China," Arabian Journal of Geosciences, vol. 11, no. 22, p. 714, 2018.

[24] Z. Huang, X. Z. Li, S. J. Li, K. Zhao, and R. Zhang, "Investigation of the hydraulic properties of deep fractured rocks around underground excavations using high-pressure injection tests," Engineering Geology, vol. 245, pp. 180-191, 2018.

[25] Q. Li, X. X. Meng, Y. B. Liu, and L. F. Pang, "Risk assessment of floor water inrush using entropy weight and variation coefficient model," Geotechnical and Geological Engineering, vol. 37, no. 3, pp. 1493-1501, 2019.

[26] B. Li, Q. Wu, X. Q. Duan, and M. Y. Chen, "Risk analysis model of water inrush through the seam floor based on set pair analysis," Mine Water and the Environment, vol. 37, no. 2, pp. 281-287, 2018.

[27] W. T. Liu, Q. Li, and J. Y. Zhao, “Application on floor water inrush evaluation based on AHP variation coefficient method with GIS," Geotechnical and Geological Engineering, vol. 36, no. 5, pp. 2799-2808, 2018.

[28] W. B. Sun and Y. C. Xue, "An improved fuzzy comprehensive evaluation system and application for risk assessment of floor water inrush in deep mining," Geotechnical and Geological Engineering, vol. 37, no. 3, pp. 1135-1145, 2019.

[29] Y. F. Zeng, "Vulnerability index method based on partition variable weight theory," in Research on risk evaluation methods of groundwater bursting from aquifers underlying coal seams and applications to coalfields of North China. Springer Theses (Recognizing Outstanding nnnnnnnD. Research), Springer, Cham, 2018.

[30] D. K. Zhao, Q. Wu, F. P. Cui et al., "Using random forest for the risk assessment of coal-floor water inrush in Panjiayao coal mine, northern China," Hydrogeology Journal, vol. 26, no. 7, pp. 2327-2340, 2018.

[31] G. Li and W. T. Liu, "Uncertainty analysis of water-inrush from floor induced by deep mining," Geotechnical and Geological Engineering, vol. 37, no. 1, pp. 317-325, 2019.

[32] T. T. Li and C. Y. Wang, "Numerical simulation study on formation and evolution process of water-inrush channel in floor under high water pressure," Geotechnical and Geological Engineering, vol. 37, no. 4, pp. 3007-3012, 2019.

[33] Z. E. Ruan, C. P. Li, A. X. Wu, and Y. Wang, "A new risk assessment model for underground mine water inrush based on AHP and D-S evidence theory," Mine Water and the Environment, vol. 38, no. 3, pp. 488-496, 2019.

[34] X. T. Wang, S. C. Li, Z. H. Xu, P. Lin, J. Hu, and W. Y. Wang, "Analysis of factors influencing floor water inrush in coal mines: a nonlinear fuzzy interval assessment method," Mine Water and the Environment, vol. 38, no. 1, pp. 81-92, 2019.

[35] J. Han, L. Q. Shi, X. G. Yu, J. C. Wei, and S. C. Li, "Mechanism of mine water-inrush through a fault from the floor," Mining Science and Technology (China), vol. 19, no. 3, pp. 276-281, 2009.

[36] X. Y. Hu, L. G. Wang, Y. L. Lu, and M. Yu, "Analysis of insidious fault activation and water inrush from the mining floor," International Journal of Mining Science and Technology, vol. 24, no. 4, pp. 477-483, 2014.

[37] S. L. Liu, W. T. Liu, and D. W. Yin, "Numerical simulation of the lagging water inrush process from insidious fault in coal seam floor," Geotechnical and Geological Engineering, vol. 35, no. 3, pp. 1013-1021, 2017.

[38] W. H. Shi, T. H. Yang, H. L. Liu, and B. Yang, "Numerical modeling of non-Darcy flow behavior of groundwater outburst through fault using the Forchheimer equation," Journal of Hydrologic Engineering, vol. 23, no. 2, p. 04017062, 2018.

[39] S. C. Li, J. Wu, Z. H. Xu, and W. M. Yang, "Mechanics criterion of water inrush from the coal floor under influence of fault and its engineering application," International Journal of Geomechanics, vol. 19, no. 5, article 04019022, 2019.

[40] B. Li, W. Q. Zhang, B. Gao, and J. D. Yuan, "Research status and development trends of mine floor water inrush grade prediction," Geotechnical and Geological Engineering, vol. 36, no. 3, pp. 1419-1429, 2018.

[41] State Administration of Work Safety and State Administrate of Coal Mine Safety, Stipulation on Prevention and Control of Coal Mine Water, China Coal Industry Publishing House, Beijing, 2009.

[42] W. Qiao, Study on the Water Abundance Regularity of Deep Fracture-Karst Aquifer and the Critical Evaluation of Water Inrush from Coal Floor in Coal Mine, China University of Mining and Technology, Xuzhou, 2011.

[43] W. Y. Hu, "The characteristics of karst and deep coal mine karst water hazards in eastern North China," Coal Geology of Exploration, vol. 38, pp. 23-27, 2010.

[44] W. Qiao, W. P. Li, and C. X. Zhao, "Water inrush coefficientunit inflow method for water inrush evaluation of coal mine floor," Chinese Journal of Rock Mechanics and Engineering, vol. 28, pp. 2466-2474, 2009.

[45] C. X. Zhao, The Water Inrush Mechanism and Governmental Mode of Deep Karst in Huaibei Mine, China University of Mining and Technology, Xuzhou, 2015.

[46] L. Q. Shi, M. Qiu, W. X. Wei, D. J. Xu, and J. Han, "Water inrush evaluation of coal seam floor by integrating the water 
inrush coefficient and the information of water abundance," International Journal of Mining Science and Technology, vol. 24, no. 5, pp. 677-681, 2014.

[47] J. Sun, Y. Hu, and G. M. Zhao, "Relationship between water inrush from coal seam floors and main roof weighting," International Journal of Mining Science and Technology, vol. 27, no. 5, pp. 873-881, 2017.

[48] B. H. Guo, T. Cheng, L. Wang, T. Luo, and X. Y. Yang, "Physical simulation of water inrush through the mine floor from a confined aquifer," Mine Water and the Environment, vol. 37, no. 3, pp. 577-585, 2018. 